\title{
Construction Method and Performance of Bugis Traditional House in Wind Disasters
}

\author{
Hartawan Madeali", B. Suhendro , E. Pradipto*, A. Kusumawanto ${ }^{\#}$ \\ \# Department of Architecture, University of Hasanuddin, Km 6 Poros Gowa-Malino,92171, Indonesia \\ E-mail:hartawanmadeali@yahoo.com-hartawan@unhas.ac.id \\ *University of Gadjah Mada, Yogyakarta, Indonesia
}

\begin{abstract}
Bugis ethnic in South Sulawesi Province, Indonesia is known as an old tribe who domiciled in the south peninsula of Sulawesi island. They have characteristics of high legacy, culture by the script called lontaraq and life in a traditional stilt house called bola ogi. This house was built in certain methods and become a research problem. The goal of this study is to reveal the construction method and the performance of the Bugis traditional house in facing of wind disaster. The research methods are field observation and in-depth interview. Field observation to reveal the old construction methods of 100 years traditional the Bugis house and its performance in collapse by wind disasters. In-depth interview to strengthen information. The research revealed that Bugis house made of wood and its built-in certain construction methods called mappasituppu. Structure system consists of the main and secondary structure which is joined together rigidly an appropriate hierarchy. The part of the structural member is setting follows natural way. The wind attack saw that building structure collapse step by step depend on its function in the structure as a whole. The lesson from Bugis in construction method is the part of the structure system best to design in the proper strength hierarchy. The strength, structure hierarchy is the maximum strength part of structure equal to the minimum strength of the structure which supports them.
\end{abstract}

Keywords — wind disasters; building structure; contruction method; traditional house; Bugis house.

\section{INTRODUCTION}

Wind disasters have two sides in real life. It brings both sadness and happiness. Condolences caused by death, and destruction properties. Positive thing caused by force of people to improve knowledge for the better next solution. Wind disaster and another disaster not only follow by sorrow but also bring knowledge behind it. The Impact of the wind disasters not only occur at present, but also in the past. Traditional house as a monumental man creature has been tested in the natural laboratory in a long period to defense this disaster. That means the traditional house contains abundant and wisdom knowledge.

The superiority of a traditional house is to fulfill needs in next development became their characteristic. Bugis ethnic in South Sulawesi has the specific traditional house. This house concealed uncovered science as well as the traditional house in their region. South Sulawesi Province in Indonesia generally flowed with the wind in limit direction. It is blown in this area from 2005 to 2009 noted in range west and east direction. This wind some time blow in high speed, especially at the end and early years. Bugis ethnic who lives in the stilt house in that season for a long time is the fact that the house has a specific one to make it stand until today 2017.

Bugis ethnic has an inherited high legacy. Stilt traditional house and lontaraq (Buginese ancient script) is evidence of the legacy. Lagaligo is the most popular lontaraq in the world as the second Memory of The World. Bugis traditional house in the form of stilt has been a stand in a long time as long as the existence of Bugis culture. This phenomenon was found in the lontaraq description. Lontaraq Meong Mpalo (MPL) and Attoriolongnge RI Wajo (ATRW) explaining that the event which is told in the story, getting a place in that house. The existence of a Bugis stilt house in lontaraq indicated that the age of the stilt house is older than lontaraq age because it has been written in that house. Assessment of lontaraq time by expert exist in the 14th century [1].

The existing of the Bugis traditional house as a stilt house was described in MPL and ATRW. The script MPL says that the cat king (Meong Mpaloe) falling and climbing until the attic [1]. A similar explanation of those house form also found in ATRW, it says that a boy who playing seed under the house call his father for his hungry. The roof cover on this house was used reeds [2]. Another explanation in this script describes the life principle of Bugis life called 
maradeka. These life principles explain the hierarchy of human freedom. There are three levels of freedom; unlimited, restriction, and know them self. This principle analog to the space function in Bugis traditional house vertically. The lower space function for livestock. The middle space for a human being. The highest space for sacredness and purity.

This house made of wood as the main building materials. The old house built from old building material and the availability of old information from Bugis script become an interesting topic to explore ancient knowledge in building construction. Bugis traditional house as one of the oldest construction methods in its location and susceptible wind disaster become a good research question. Why this structure able to stand in a long time. What's the secret science hiding behind it?

Traditional house not only functions as a commodity and evidence of culture but also connecting knowledge from the past to the future. This research goal is to reveal the performance of the Bugis traditional house after hitting by wind disasters. This study derived from field observation in some traditional building damage after wind attack in Sidrap regency South Sulawesi Province in 2012. The point of this research is to uncover the science from wind disasters in a traditional house. Disasters bring knowledge and spirit force to improvement better life.

\section{MATERIAL AND METHODS}

Building physically appears in beauty can be impressed by the availability of the structural system. The structure is essential to form and prevent the building stability. This word has been explained from the past by Henry Wooton in the seventeenth century. The part of the building which satisfied the need for firmness is the structure [3]. Structure system in the traditional house seems to be forgotten by researchers.

A research concern in the traditional building structure is scarce sources. The reference on this topic is an axis is limited. This research is one of effort to full fill that scarcity and becomes the documentation of ancient inheritance.

The traditional house exists everywhere on our planet. This house became the sign of glory from the clan in the past. Their ability for a serving function in long period as proved of the ingenuity both in architecture and structure science. The traditional Malay house has awn potential and ability to develop nicely still depend on the sensitivity and good relationship with surrounding [4].

Traditional building in the world well known as the wise structure which is built in a friendly way around the location. This building has a high ability to stand firm from general disaster evolved. Turkey traditional house made of wood which is categorized as weak material presented a good resistance to earthquake [5]. This building structure analyzed by using SAP 2000 software. The result is this structure more ductile compared with reinforced concrete and masonry structures [6].

Sunda traditional house in Indonesia performance their ingenuity in stay firm from an earthquake. After an earthquake in Kampung Panjallin in 2007 and 2009 field observation was conducted and found that the traditional house is more resistant than concrete house [7].
A Bugis traditional house built in different ways depending on its location, south, and north. The specific Bugis traditional was found in the north area [8]. This structured system expands knowledge in the ingenuity of Bugis technician. The case of this research takes location in the area. Structure system in the Bugis traditional house has been changed as long as time in development. Exploration in the remote Bugis area has been found the structural system of Bugis traditional house in 4 type system; there is the fifth round beams, the fourth round beams, the second round beams, and the square beams. Those different types of structural system are found in the connection between main the structure and roof structure [9]. All of the samples have the same orientation as west-east.

Bugis script explanation about them a traditional house, covered good measurement of happiness, the position of wood in the best place of the column, and the time for doing something. Script roll no 14 explained that when a bent shape of wood uses as a post in a house, it is best for placed in the center position [10]. The placement of wood considered its position in nature since alive believe by Shinto society that it is better for placing it according to position naturally. Wood when growing hit by the sun from the east better placing in east orientation (same orientation) if it uses as building materials [11].

The description above explains that traditional building which built by traditional technology in a certain location contains a wise knowledge to prevent human injuries and to minimize building damage from natural disasters. Influence of wind disasters forces the scientist to make a hard effort to minimize destruction through research. Research has been done by both exploring new technology and advanced wind destruction management system. The better way finds for a solution the high impact conceals in disasters. Seminars and research development seem to be always late for getting way out of the problem

Wind disasters destroy buildings in chain damage. Destruction of building envelope possibly caused damage to property inside. This property became loose of value. The effort for reduction effect of wind disaster is better done by collaboration multiple academic association institutions for different natural disasters and among academic societies and non-academic organizations working on disaster [12].

The impact of hurricanes not only bring effect in infrastructure and properties but also in population. Model extensions show that change in the white and young adult population is more immediately and strongly affected than changes for blacks and elderly residents. Negative effects on the population are stronger in counties with lower poverty rates [13]

Improvement of wind disaster management in Latvian suggested doing by the interaction between business, society, and state. The costs in the elimination of wind disaster are associated with restoration of infrastructure, prevention of forest devastation, liquidation of damage in port, and restoration of power line operation [14]. The same effort has been done in South Africa. In this area, National Disaster Management Centre requires to develop a general analysis of the string wind hazard. This effort revealed the map of wind strong [15]. 
The Negative effect of wind disasters has two impacts on investment reciprocal. Devastation infrastructure and properties have a direct impact and investment for rehabilitation and restoration. The method used to reveal the performance of the Bugis traditional house to defend from wind attack is field observation and in-depth interview. Field observation concern in Wetteqe, the village in Sidrap regency, South Sulawesi Province, which experienced a wind attack in 2012 February 24th. In-depth interview considered of getting the true information related to construction methods by Bugis expertise.

\section{RESULTS AND DISCUSSIONS}

Results and discussion consist of 3 point discussions. The composition of paper begins with the ancient Bugis traditional house, followed by the structure system development and its performance in wind disasters.

\section{A. An Ancient Bugis Traditional House}

The Bugis traditional house was built following the specific way in construction method. This method arranges the shape of a member in place at the particular position of the column and beam. The best position of a column depends on the grade of bent shape. The higher bent shape of member the center position location appropriate is. A center position defined in two ways, the center row in the center building and the center row in the perimeter. The straight shape of the member has a good position in the corner. The bent shape of column showed in fig. 1 .

Beam arrangement in the Bugis traditional house set leaning outside. This beam located at the center of building vertically and horizontally in longitudinal directions. To determine the beam orientation, done by placing the straight line along the column and adding three fingers at the outside direction of buildings at the column bottom. The result of this measurement set beam position leans about $1^{\circ}$ to outside.

The structural system which composed as mention abovecalled mappasituppu. Марраsituppu means optimize energy of falling the leaning bent member by pulling each other.

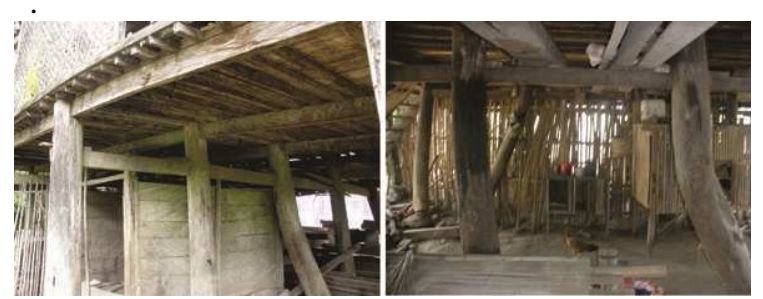

Fig. 1. Bent column in center position

Structure system consists of the primary structure and secondary structure. The primary structure formed by column and beam. This structure divides into two parts (upper and lower). The joint between column and beam categorize as fixed joint like mortise and tenon. Strengthening joint, helping by inserting a piece of wood called Pollacaq on one side, upper or bottom of a beam. Secondary structure connected to the primary structure as detachable. Generally the secondary structure functions to the formed wall, floor, and roof. The joint between the primary structure and the secondary structure is pinned joint and free standing. Joint wall structure to the primary structure is pinned joint. Joint floor structure to the primary structure is free standing joint. Joint roof structure to the primary structure is free standing joint.

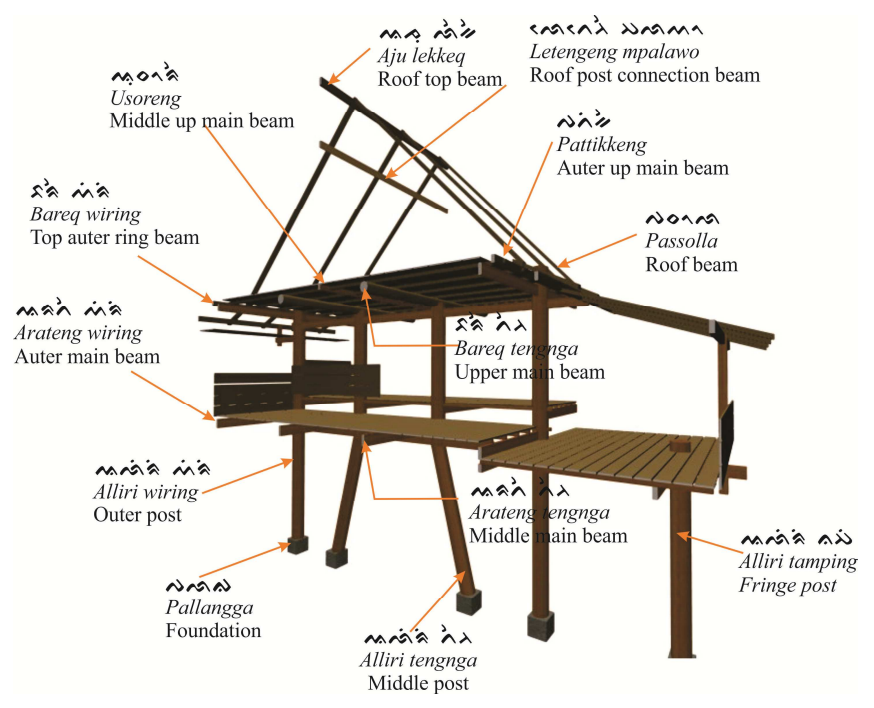

Fig. 2. An Ancient Bugis house structure

Joint among part of the Bugis traditional house vertically take in two locations. The first joint is the joint between earth and the body of the buildings. The second is a joint between the body of the building and the roof. Both joint is free standing. The bottom end column placed on wood or stone called palangga to separate direct contact of column base to earth. Palangga function as load and material protector. The roof structure element notch on the lower end of roof beam and placed it to the primary structure in a freeway.

Dimension and material quality are better for the primary structure than secondary structure. The best quality and quantity have a high position by placing it in the one of the center column called posiq bola in meaning the center of the house. Column and beam section used by an old house is a circle, eleven facets, octagons, and rectangular. Beam section was found in two parts, upper and middle. Upper part beam section use circle, eleven facets, octagons and rectangular. The central beam uses rectangular section. Because of the limitation of wood, natural sources, the most prefer section after the 1970s is rectangular in various sizes.

The connection among members in the Bugis traditional house is a prohibition for longitudinal member joint. The intersection joint just found between column and beam which apply mortise and tenon joint. Column and beam is a piece of wood without the longitudinal joint. The material used for construction getting from nature. There are wood, bamboo, and leaves or reeds. The wood used for the primary structure, wood and bamboo used for secondary structure, and leaves or reeds used for covering as building envelopes as wall and roof.

Bamboo materials which use as a secondary structure in The Bugis traditional house are suitable to the current research. The bundled bamboo split is a new bamboo construction, development not recommended to be used as a structural element that carries the purely compressive load. Application of natural sources in the Bugis house structure follows the natural law. The quality and quantity considered 
in equal to function. The high quality of materials set for bearing the high loads. The low quality of material setting is for secondary structure.

\section{B. Development of The Bugis Traditional House In Structure System}

Structure system of the Bugis traditional house has been changed. The image in fig. 3. Show two structural systems in a different period. The first left is the old house, and the right one is a new house. The old house was dismantled in old site and carry to other sites for rebuilt in a new one. The new house is the house which first time built on the site. The shape of the column in the old house appears in a different shape to the new one. The old was using the leaning bent shape, but the new one uses the straight shape.
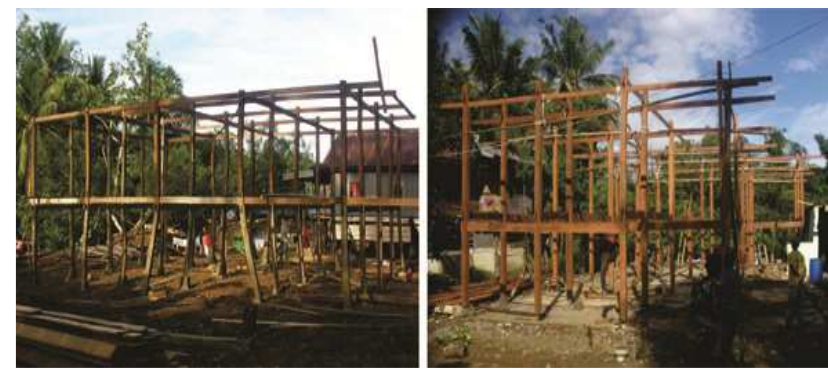

Fig. 3. Comparison between old and new Bugis building structure

The Bugis traditional house currently built using a sharp straight column. Based on an interview the consideration of using straight column is an aesthetic reason. The straight shape column is more beautiful than a bent shape column. The Mappasituppu construction method for the straight shape still uses as the role. This method was explained in section 3.1. The Bugis traditional house structure system in this time has affluence by the development of technology. The material has been altered from a natural material with a modern one. Roof sheeting replaced from reeds to corrugated metal, wall covering replaced with metal and glass, joint system in roof structure replaced to bolt or screw, and nail.

A construction method in development has been changed, especially to follow the modern building material requirement. A cord to tie as traditional methods replaced by nail, bolt, and screw. Roof sheet in the past tied to the roof structure on one side of the roof. This setting makes it allowed, rotate in one side as pin joint. Metal corrugated roof nailed in all sides of sheeting to make it fixed. The structural system of Bugis house is a unity of several structure systems. Roof, wall, and floor are the structural system for itself, despite the primary structure. Joint among part of structure internally has specific manner. Joint among structure system doing by pin and freestanding joint. The strength of joint among the member of the structure is designed properly. The real structural system is the primary structure. The roof, wall, and floor structure are attachment structure as secondary structure.

Although material and section structure has been changed in the Bugis traditional house the central principle of construction method is still followed in nowadays. The joint principle among member of the structure is same as the old method

\section{Bugis Traditional House Performance After Wind Attack}

Bugis traditional house performance explained in this session take from site observation after wind attacks derived from wind disaster in 2012 February 24th. This horrible wind caused 47 unit house destroyed, four units in high-risk damages category, and 13 units in low-risk damages category. This house use structure system in common with the last construction methods. Low-risk damage category showed in fig. 4 and 5. High-risk damage is the result. The classification of low and high- risk damage structure in this section follows the authority stipulation at the time.

Discussion in this part explained by following the hierarchy of traditional house damages after experience wind attack. Expression of explanation starts from the low risk of the high risk. The picture display was taken seven days after severe wind attack.

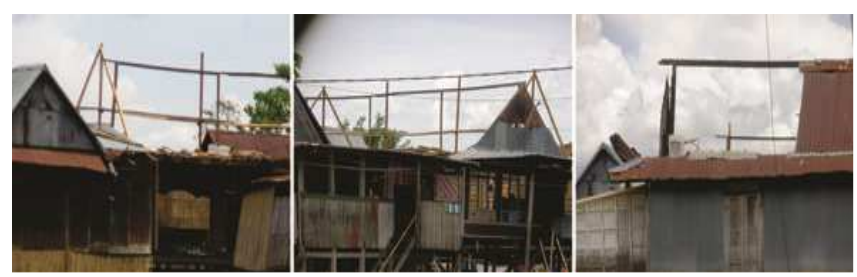

Fig. 4. Roof sheet flew with the wind

The lowest risk damage of Bugis house during a wind attack is roofing sheet blowing in the wind, see fig 3 . Common material using to cover roof is the corrugated metal sheet made of zinc. This sheet connected to the roof structure of the nail. Sheet roof structure support by three pieces of beams in various dimensions, common size $2 \times 4 \mathrm{~cm}$. This level destruction occurs yearly in the Bugis area and surrounding.

The roofing material in the past was reeds or leaves. This material tied on one side at two ends follows pin joint. When the wind attacks, the roof material have an opportunity to rotate or wave on one side to release energy which hit it. This condition is different from the recent method. Corrugated metal constructed by a fixed joint to the roof structure. The wind load, in this case, allow all the energy transfers to the roof structure.

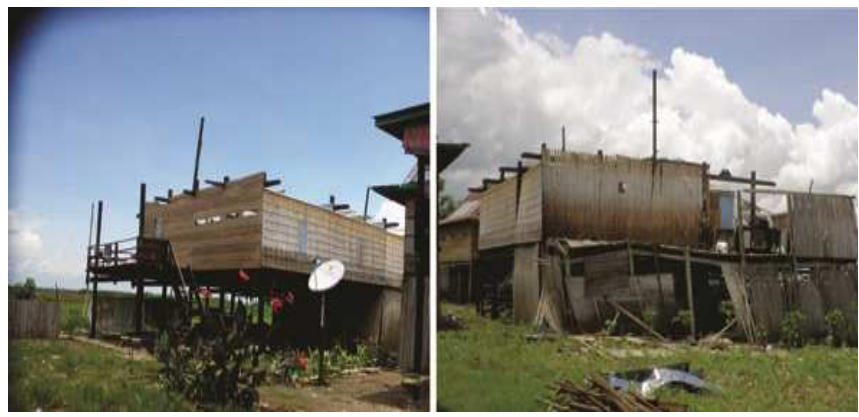

Fig. 5. The roof structure destroyed by the wind 


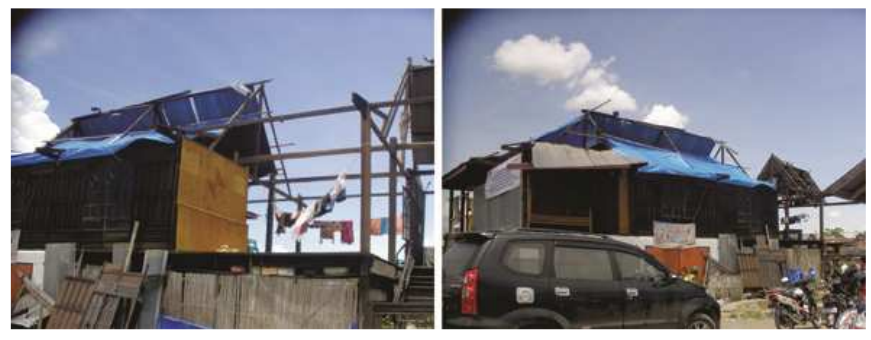

Fig. 6. The wind destroyed part of the wall

High-risk classification damage caused by the wind is starting in half wall destroyed. The wall material used in this house is a wood plank constructed fixed between $4 \times 4$ wood beam frame. Wall joined to the primary structure using a piece of wood which nailed in two ends. The connection between wall and main structure have the opportunity for rotating freely in two directions. One side free is moving horizontally and the others vertically.
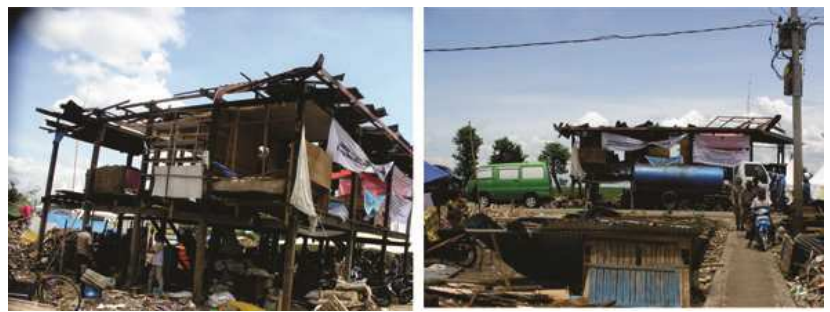

Fig. 7. Wall and roof structures destroyed by the wind.

The next damage structure after half wall destroyed is all the walls. The primary structure and the floor structure at this level still firm without damage or caused a victim to people. The wall structure failure not affected by the structure which supports them.

The floor structure in this level damages stays in a good position. This condition shows the remarkable design principle. Part of the structure system in Bugis traditional house experience damage in a certain stage by destroying them self.

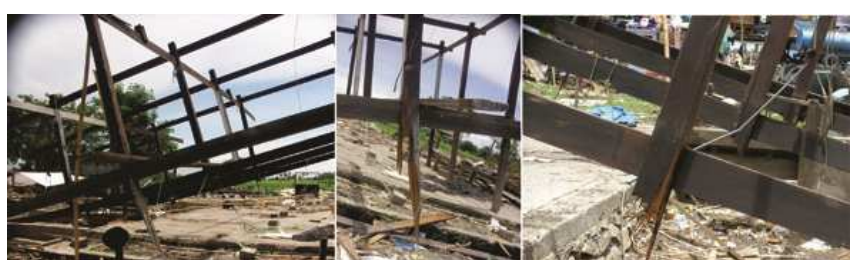

Fig. 8. The lower column group has been broken due to the wind.

The last one structure damage is the lower part of the column was broken in the primary structure. In this phenomenon, the upper part of the main structure is stronger than the lower one. Based on information the floor structure at this damage level still stays at as well as position. The picture in fig. 8 was taken after the floor structure has been removed. The upper part of the primary structure in Bugis traditional house function as space for people. There are two parts of the Bugis traditional house which stay firm. The upper main structure and the floor structure. This case shows that the primary consideration in structure design is the safety of the human.
Floor structure in Bugis traditional house assembles by putting a wood plank on the little beam. This beam is placing on main longitudinal beam in freestanding ways. The wood plank sets separated in limited by column rows in a longitudinal direction. Wood plank as the floor surface design like dilatation principles in a modern structure. The application of this principle allows wood plank to be moving freely when the load applied to the floor surface. The joint between light supporting beam in freestanding improves the ability of floor structure to release load impact of the primary structure.

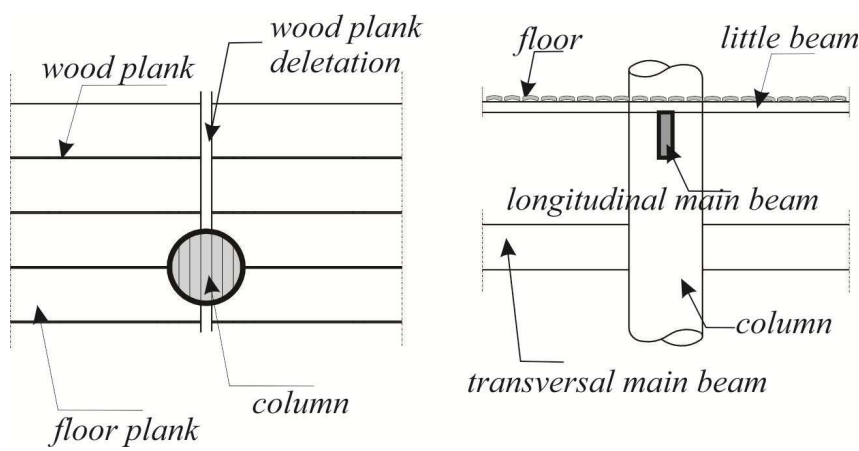

Fig. 9. Floor structure of Bugis house

Part of the traditional house structure which damage after hitting the wind hazard bring new knowledge into the building material maintenance. Roof sheeting and envelop structure like wall are the part of the building structure which easies for maintenance.
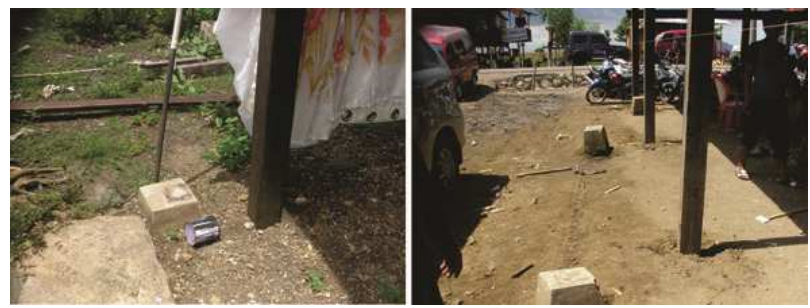

Fig. 10. The house has jumped by the wind

The wind effect in fig $5-7$ give a prove the unity of the structure system to prevent people in safety. House structure in that picture was found jumping leave the old position to the new one. This phenomenon explains naturally that the limit of building defends wind loads which hit the body of the building until its structural failure.

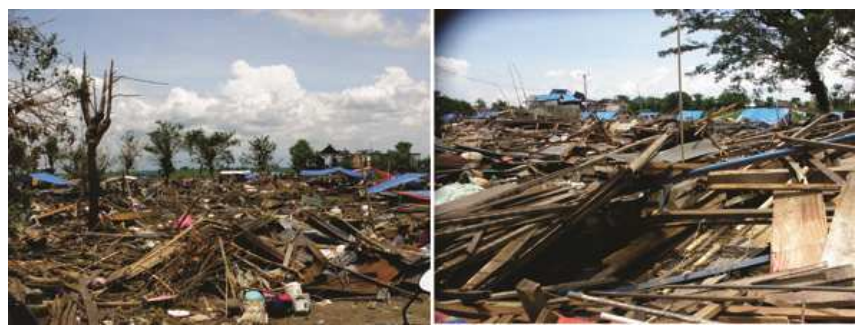

Fig. 11 Total damage due to tornado

The final battle of the Bugis traditional house to defend the human safety is the lower part of the structure are breaking. The last structure destroys in Bugis house structure 
is the floor structure. This structure particular provided for humanity. Bugis traditional house damage caused by wind disasters resumed in the table below.

TABLE I

Structure Destruction Phase By The Wind Disasters

\begin{tabular}{|c|l|l|}
\hline $\begin{array}{c}\text { Step of } \\
\text { Damage }\end{array}$ & \multicolumn{1}{|c|}{$\begin{array}{c}\text { Structure } \\
\text { Destruction }\end{array}$} & House Position \\
\hline 1 & Roofing sheets & Fixed \\
\hline 2 & Roofing structure & Shifted \\
\hline 3 & Wall in half part & Shifted \\
\hline 4 & Total Wall & Shifted \\
\hline 5 & $\begin{array}{l}\text { The lower part of the } \\
\text { column }\end{array}$ & Shifted \\
\hline 6 & Total & Shifted \\
\hline
\end{tabular}

Nature is great in power. The most talented man in mastering technology the more significant challenge will be. The Bugis traditional house has been designing an appropriate structure system for battle load, but in nature, it is not enough. The extraordinary power of wind attack and the limitation of man's creation, finally eradicate the building structure, See fig. 10. A Column in Bugis traditional house has the biggest size $(11 \mathrm{~cm} \times 11 \mathrm{~cm}-15 \mathrm{~cm} \times 15 \mathrm{~cm})$ among another member. This large size made of the best quality wood among other member structure. The large and the best quality breaks in debris.

The explanation above teach to the next generation that Bugis traditional house has a great effort to defend wind load in a friendly way. The fundamental consideration in structure system design is the safety of human life. The part of the structure stand fight until the end, but they do not destroy the part of structure system which more important than us. Roof sheet leaves roof structure without damages the roof structure; roof structure failure without destroying the primary structure; wall structure failure without destroying the primary structure; lowest column breaks in the condition of the upper column in firm unity. The floor structure is the last system damage from wind disasters. This structure is functioning as the space for man living.

Roof sheet bearing wind load on the limit, the power they have until its leave the roof structure system. The roof structure bears wind load until the end power they have, but they release them self without destroying the structure system which support is. The body of the building leaves the position by jumping for protecting the human life in the house.

There are three ways of structure system strategy to protect from wind attack; a) Dimension section area. b) The quality of materials. c) Joint system. Dimension sectional area in the Bugis traditional House follows the hierarchy of the system. The more critical structure-function the largest dimension they have. The quality of materials, structure formation follows the hierarchy of the structural system. Main structure made of better quality than the secondary structure. The main structural member dimension has larger than the secondary structure. The main structure has rigid joint, and the joint between other secondary structures has pin joint.

The explanation above introducing to create a good rule of a proper fundamental consideration in the structure design.
The high strength of the secondary structure is equal to the minimum strength of the primary structure. The limit strength of the structure and the part of the structure is equal to the elasticity point of the next structure where support them. This rule is applied to the part of all structure element respectively.

An old Bugis traditional house has a rectangular plan shape. They orientation follow west-east rule direction. The rule of the basic rectangular shape formed from the short and long side. This rule applied in the plan of the Bugis traditional house by placing the short side to east-west orientation. Front and back side of the house in the east-west orientation. This orientation is appropriate to wind direction in this region. Wind direction in south Sulawesi peninsula commonly from west to east reciprocal yearly. The surface hit by the wind on the short side of the building means the low load will hit that surface.

The structure lessons hiding behind this disaster are how to design appropriate construction method for minimizing the negative effect of wind disasters. The Bugis traditional structure system has been designed in the best way of defending a wind attack. The principles, design are understanding the natural phenomenon and find the best way to stand by friendly do not the offense to nature. The principle design of the Bugis traditional house structure is analog to the Bugis life principles. The life principle of Bugis according to the script is life maradeka. The highest level in maradeka has known them self. The structure system principle to prevent people from wind disaster have the same to those principles. The lowest hierarchy structure prevents itself in maximum power and never cause damage to the structure which supports them.

The other lesson, in this case, is the part of the secondary structure which prone to damage from wind disaster placed in a natural way for maintenance. The sheet roof as the first damage in wind attack is the part of the structure which an easy to maintain. The wall structure damage is the part structure which an easy to repair in a proper position. The essential consideration of the Bugis traditional house in structural design is the human safety. The case explains above showed that the last structure stand after wind attack is the structure of human space. Man space in Bugis traditional house located in the middle part of structure vertically as in fig.8.

\section{CONCLUSIONS}

A Bugis traditional stilt house was found in the ancient script. This house was built in specific construction method called mappasituppu. In the line of live development, this structure has a been changed in shape of the column, but still secure in them ancient construction method. The performance of structure in wind attack is defended according to them a position in the structure as a whole. The main structure is the latest defender. The collapsing process of the structure of the wind follows the step by step hierarchy.

Traditional building considered as the building has been tested in the magnificent natural laboratory. It is grown in long time experience makes them great performance in handling a natural disaster in which it develops. The wise way from study traditional building is to know how it built 
and expanded the soul of the system in a modern way. Structure element breaks itself in the limitation of his strength and not delivered the load to the structure which supports them. The wise rule of strength design is the maximum power of the secondary structure equal to the minimum power of the primary structure. The lesson in structure design from Bugis is the building structure be best for design by the hierarchy of strength. The main structure should be design stronger than the secondary structure

\section{REFERENCES}

[1] Rahman, Nurhayati, "The Wisdom of Buginese Living Environment Based on Meong Mpaloe," La Galigo Press, 2009, Makassar.

[2] Anonymous, Wajores Ancient Script.

[3] Angus J. Mac Donald, Structure and Architecture, Oxford Auckland Boston Johannesburg Melbourne New Delhi, Architectural Press, 2001, xi.

[4] Nangkula Utaberta, Nurhananie Spalie., 2011. Evaluating the Design and Construction Flexibility of Traditional Malay House. Proceeding of the International Conference on Advanced Science, Engineering and Information Technology 2011.

[5] Dogangun, Adem, Tuluk. O. Iskender, Livaoglu. Ramazan, Acar. Ramazan, Traditional Wooden Buildings, and Their Damages during Earthquakes in Turkey, www. Elsevier. com/locate/engfailanal, Engineering Failure Analysis 13 (2006) 981-996.

[6] Mizam Dogan, Seismic Analysis Of Traditional Buildings: Bagdadi and Himiz, Anadolu Üniversitesi Bilim ve Teknoloji Dergisi - A 11 (1)
Uygulamalı Bilimler ve Mühendislik Applied Sciences and Engineering Cilt/Vol.:11-Say1/No: 1 :, 2010, 35-45.

[7] Sugeng.T, Andi.H, "Kampung Panjalin Tenacity On Hard Soil In Earthquake Zone III, Canadian Journal on Environmental, Construction and Civil Engineering Vol. 3, No. 1, January 2012, pp 26-37.

[8] Hartawan, Bambang.S, E. Pradipto, A. Kusumawanto, "The System Structure As A Determinant of Buginese House In South Sulawesi," 2015. EAC 2 Conference Proceedings, pp 55-68.

[9] Hartawan, Bambang.S, E. Pradipto, A. Kusumawanto, "The Change of Structure System of Bugis House in South Sulawesi, Forum Teknik, Scientific Technology Magazine, Vol. 36 No.1, January 2015. 1-12.

[10] Robinson, Kathryn dan Paeni. M, "Time Traces" History, Culture, and Social Life in South Sulawesi, 2005. Ininnawa.

[11] Cohen, David, McKay. Sherry, Brock. Linda, Cole. Raymond, and Prion. Helmut, 1996, Wood construction in Japan: Past and present, Forest Products Journal; Nov/Dec 1996; 46, 11/12; ProQuest pg. $18-24$.

[12] Yukio Tamura. Wind-Induce Damage to Building and Disaster Risk Reduction. The Seventh Asia-Pacific Conference on Wind Engineering, November 8-12, 2009, Taipe, Taiwan

[13] Logan, J. R., Issar, S., \& Xu, Z. (2016). Trapped in place? Segmented resilience to hurricanes in the gulf coast, 1970-2005. Demography, 53(5), 1511-1534.

[14] Mareks Silovs, Jelena Malahova, Janis Ievins, Vladimir Jemeljanovs, Karlis Ketners., Wind-Related Disasters Management and Prevention improvement strategy., $20^{\mathrm{Th}}$ International Scientific Conference Economics and Management - 2015 (ICME-2015)

[15] Kruger, A. C., Pillay, D. L., \& van Staden, M. (2016). Indicative hazard profile for strong winds in South Africa. South African Journal of Science, 112(1), 1-11. 